H. Gerischer showed how the measurement of A.C. polarization resistance can help with the analysis of processes in metal deposition. Thus, in the case of silver ion deposition on silver from simple salt solution, it appears that the rate of the reaction is controlled by the building into the surface of the metal atoms and that discharge of the ions is rapid. Correspondingly, interesting data were presented by $H$. Fischer, who treated the various stages of action of an inhibitor in metal deposition in terms of the theory of crystal growth. T. P. Hoar described experiments which strongly suggest that dissolution of an anode which is undergoing polishing or brightening occurs through a compact solid film on the surface and that this film dissolves its outer surface as fast as it is formed at the metal/solution interface. This account summarized the points in favour of a theory which probably represents the essential solution of the long-standing problem of electropolishing. W. F. Franck showed that the polarization resistance measured at an attackable electrode suddenly changes at the equivalence point of a titration and illustrated how this property could be used in analysis.

Among other subjects treated were : the definition of a chemical potential in an electrochemical system ; the influence of the electronic structure of a metal on the rate of an electrochemical reaction taking place at its surface; cathodic reduction of oxygen to hydrogen peroxide; the inhibition of corrosion ; and the electrokinetic potentials of sols in silver iodide. The papers and the discussion material will appear in the Comptes rendus of the Committee, which is published yearly.

The Commission on Electrochemical Definitions and Nomenclature (J. O'M. Bockris, R. Defay, E. Lange, R. Piontelli, P. van Rysselberghe and G. Valensi) held several sessions in London and Cambridge and will publish a second report in the Comptes rendus for 1952. A Commission on Experimental Methods in Electrode Processes was formed, consisting of J. O'M. Bockris, H. Gerischer, R. Gauguin, R. Piontelli and G. Valensi, and will make its first report in 1953. The total attendance at the meeting was about seventy. The next meeting will be held at Stockholm in July of this year.

\section{THE TIAN-CALVET MICROCALORIMETER IN SEED GERMINATION STUDIES}

DROF. H. PRAT, of the Institute of Biology: University of Montreal, has described some preliminary investigations of thermogenesis in germinating seeds of various cereals, flax, tomato, etc., using the new Tian-Calvet calorimeter (Canad. $J$. Bot., 30, 4, 379; 1952). The use and advantages of the new instrument are indicated.

The type of thermogenic curve obtained from the germination of wheat seeds seems likely to have a general application. Immediately upon the contact between the dry seed and water there is a quick, then a falling off, and then a more slowly developing, production of heat; that is, the curve shows a steep rise and fall and then a slow steady rise. The initial phase of rapid rise and fall in the curve is common to both living and dead seed and is ascribed to physico-chemical thermogenesis. The ensuing phase of depression may be endothermic or weakly exothermic. The third phase of steadily increasing heat production, which corresponds to the onset of growth, with its concomitant respiration, is described as biological thermogenesis.

By using the new microcalorimeter it is possible to determine with considerable accuracy the effects on the thermogenic curve of such factors as temperature, dehydration of seed, ageing of seed, and additions of substances to the soaking water; for example, biological thermogenesis is increased by indoleacetic acid at low concentrations and diminished by alcohol and iron sulphate. A comparison of the thermogenetic responses of different seeds opens a wide field of study : the interesting and suggestive preliminary data which are given seem likely to have both an academic and a practical importance.

\section{RECENT MARINE BIOLOGY}

$T$

HE first two numbers of Vol. 31 of the Journal of the Marine Biological Association cover a wide field in the studies of the seas and their inhabitants.

Three papers are further instalments in their respective series. Dr. G. P. Wells contributes his sixth paper on Arenicola, dealing with the proboscis of three species and its mode of action, in which there are beautiful photographs of both the exterior and interior of the proboscis. Dr. H. G. Vevers's fourth article on the biology of Asterias rubens describes the variation in the sex ratio; the highest percentage of females occurred in the period MarchJune and the lowest during January-February, and he found no trace of hermaphroditism. In his third paper on Choetopterus variopedatus, Dr. J. A. C. Nicol discusses factors affecting the light response. Stimulation of the photogenic glands occurs through their nerve fibres; but augmentation of the response takes place locally in the glandular tissue itself. There is, however, a process of central facilitation in the nerve cord, most apparent in the posterior region of the body. The luminescent reaction is a triggered response which can be produced by a single stimulus.

There are three papers on Ascidians. Dr. R. H. Millar worked out the annual growth and reproductive cycle in Diplosoma listerianum, Ciona intestinalis, Ascidiella aspersa and Botryllus schlosseri. Each species behaved as an annual, settling as a larva, breeding and dying within a period of from twelve to eighteen months; breeding occurred in summer. Miss P. Kott, in a résumé of certain compound Ascidians of the Plymouth area, with a description of two new species, considers that Aplidium nordmanni and $A$. proliferum are forms of the same species, and that Giard's $A$. densum is synonymous with the latter; Berrill (1950) regards them as distinct species. Obviously we require comparative details of specimens from different areas around the British coasts before lumpers or splitters are accepted as authorities.

Dr. J. S. Alexandrowicz has been able to complete his investigation, begun in 1931, of the innervation of the heart of Ligia oceanica. He found three systems of nerve elements--six neurons constituting a local system, a pair of nerves connecting this with the central system, and the nerves of the arterial valves ; the alary muscles have their own innervation.

Dr. W. Wieser carried out an intensive population count of the microfauna inhabiting single tufts of seaweeds on the rocks below the Plymouth Labor- 
atory. He took samples under water in the infralittoral and littoral zones during high water, by diving, "using nothing but glasses, flippers and a belt with pieces of lead fixed to it". Eight weeds were chosen, and one sample of Gelidium corneum yielded the astonishing number of 2,818 animals per gram of dry weed, including 600 Nematodes and 1,864 specimens of Lascea rubra. Observations under water, using a modified frogman apparatus, were also made by Mr. R. Bainbridge, who describes the swimming habits of Calanus and Sagitta.

The necessity to control the bacterial contamination of mould-free phytoplankton cultures led Mr. C. P. Spencer to experiment with the antibiotics penicillin and streptomycin, the former being the more effective in keeping the culture pure. Miss B. Ross studied the changes in chemical composition at various ages of Himanthalia elongata, and found that any estimate of the chemical composition at different seasons should be correlated with the size of the vegetative buttons and thongs. Cultures of sixteen species of the smaller marine algæ, including seven flagellates, were prepared by Mr. R. W. Butcher, whose paper is illustrated by coloured figures of all the species. Finally, the first number of Vol. 31 concludes with an interesting account by Dr. D. P. Wilson of the aquarium and sea-water circulatory system at the Plymouth Laboratory.

In the second number, Dr. H. G. Vevers describes improvements in his apparatus for photographing the sea floor, whereby the camera is set at $1 \mathrm{~m}$. from the ground and records an area of $50 \mathrm{~cm} . \times 50 \mathrm{~cm}$. thus producing better definition. As the result of his surveys, Dr. Vevers estimates that near Looe there is a population of Ophiothrix fragilis at least two miles long and half a mile broad, at a density of 392,000 per acre. North-west of the Eddystone the population is even greater and reaches $1 \cdot 3$ million per acre. In both cases, tidal streams probably bring suspended food to the crowded beds, and the scavenging work of these brittle stars, whether of detritus or of sinking matter, must be considerable.

Dr. R. B. Pike has worked on the biology of the prawn Pandalus bonnieri, which is a dicecious species living in deep water. Breeding occurs from the end of October for from six to eight weeks, and the young leave the berried female from February to April in the following year, metamorphosing in June. Sexual maturity is reached in eighteen months. The maximum life-span is four years; but few live beyond three years in the Clyde area.

Dr. J. S. Alexandrowicz studied the muscle receptor organs in the Paguridæ, and Mr. Graham Hoyle the response mechanism in the Ascidians, Phallusia mammillata and Ascidiella aspersa. Prof. J. E. Harris has kept records of the breeding condition of dogfish supplied to the University of Bristol from the Ilfracombe area, and concludes that spawning starts in November and continues until July. A Fulbright scholar from Miami, Mr. R. F. Hutton, has named a cercaria from the cockle, Cercaria fulbrighti, and gives a full description of it and other parasites from this lamellibranch.

To the biological indicators of water movements in the English Channel (Sagitta and Muggicea spp.), Dr. L. H. N. Cooper suggests adding the boar fish, Capros aper (L.), the occurrence of which coincides with that of Muggicea kochi, indicating movement of water from the south-west area of the continental slope towards Plymouth, after a period of strong south-west winds succeeded by calm weather.
Hydrographical observations are recorded by Dr. W. R. G. Atkins and Miss P. Jenkins, and on the reaction of marine animals to ultra-violet light in conjunction with echo sounders by R. E. Craig and I. G. Baxter, who hope that further work will produce results of practical importance to the fishing industry.

In their first paper in a series on the vitamin A and carotenoid content of invertebrates, Mr. L. R. Fisher and Drs. S. K. Kon and S. Y. Thompson describe an investigation of the various Crustacea from the British coasts, particularly the Euphausiids, Meganyctiphanes norvegica and Euphausia superba, the krill upon which some whales feed. These contained large quantities of vitamin A, 90 per cent of which was in their large eyes, together with a high proportion of their astaxanthin. No carotene was present. The vitamin A concentration was lower in decapods, absent in the copepod Calanus finmarchicus, amphipods, isopods and Cladocera. By consuming krill, a baleen whale may take in one ton of vitamin $\mathrm{A}$, to be stored in the liver, which would yield about $2,000,000$ I.U.

The volume ends with the report of the Council of the Marine Biological Association. It is pleasant to note that for the first time the Association will be able to have a vessel specially built as a research ship. Membership has increased by 47 to 659 .

N. B. Eales

\section{PATTERNS OF SPRING MIGRATION}

IN 1950 and 1951 the British bird observatories exchanged information about the occurrences of selected species of birds. A study of this collated information by R. K. Cornwallis appears to throw some light on the pattern of migration to and through the British Isles in spring (British Birds, 45, No.9; September 1952).

The simple conception of this pattern of spring migration is one of a south-to-north movement. The birds, it is assumed, enter England at points along the south coast and proceed northwards until they either reach their breeding-grounds in Britain, or, if they do not remain to breed, strike north-west to Iceland or north-east to Scandinavia from our northern coasts. This is often assumed in ornithological writings to be what happens, though the subject is a neglected one.

Not all the facts, however, appear to fit this simple pattern. For example, certain birds which breed in Scandinavia and occur in Britain both as summer residents and as passage migrants were recorded on spring migration in 1950 in greater numbers at the more northerly bird observatories, the numbers decreasing regularly with each more southerly observatory in turn (pied flycatcher, garden warbler, lesser whitethroat, common redstart).

It is common, too, when waves of birds are recorded at the east-coast observatories, for these to occur on approximately the same date at all of them and not progressively later at the more northerly stations (redstarts, pied flycatchers, fieldfares and ring ouzels). Moreover, the greatest numbers of some birds are often observed, particularly at east-coast stations, on dates when British breeding birds of the same species have already started nesting, even when the breeding-ground lies farther north than the observatory.

A fourth fact is that at Gibraltar Point the direction of diurnal migration in the spring, as well as in the 